\title{
COMMUNICATION, AUTISM QUOTIENT AND AUDITORY BRAINSTEM RESPONSE
}

\section{Comunicación, cociente del espectro autista y respuesta auditiva provocada del tronco encefálico}

Marilia Baquerizo Sedano (1), Edward Susanibar Mesías (2), Mario Wong Egusquiza (1), David Achanccaray Diaz (3), Christian Flores Vega (4), Luis Baquerizo Sedano (1), Hugo Umeres Cáceres (2). Luis Aguilar Mendoza (1)

\begin{abstract}
The auditory pathway as a neurobiological mechanisms involved in autism can be evaluated by evoked potentials. The objective of this study was to estimate the auditory brainstem response of the pulse click, considering the latency of waves I, III and V; the interpeaks I-III, I-V, III-V and the amplitude of the wave $V$, and relate them with the formal and pragmatic aspects of communication and the autism quotient. The results showed that there are significant differences between the auditory brainstem response of the autistic group and the control group. Furthermore, in the adolescent autistic group the latency of wave $V$ and the interpeak I-V would be the indexes that would reach to predict the autism quotient.
\end{abstract}

Key words: autism, evoked potentials, auditory brainstem response.

\section{Resumen}

La vía auditiva, como mecanismo neurobiológico implicado en el autismo, puede ser evaluada por potenciales evocados. El objetivo de este estudio fue estimar la respuesta auditiva provocada del tronco encefálico a través de pulsos, considerando la latencia de la onda I, III y V; las interlatencias I-III, IV, III-V y la amplitud de la onda $V$, y relacionarlas con los aspectos formales y pragmáticos de la comunicación y del cociente del espectro autista. Los resultados demostraron que existen diferencias significativas entre la respuesta auditiva provocada en el tronco encefálico del grupo autista y el grupo de control. Además, en el grupo autista adolescente, la latencia de la onda $V$ y la interlatencia I-V serían los índices que alcanzarían a predecir el cociente del espectro autista.

Palabras clave: autismo, potenciales evocados, respuesta auditiva provocada del tronco encefálico.

(1) Neuroscience and behavioral laboratory - Cayetano Heredia Peruvian University-Peru

(2) Neurophysiology laboratory -Cayetano Heredia National Hospital-Peru

(3) Research Group on Applied Robotics and Biomechanics - Pontifical Catholic University of Peru-Peru

(4) School of Electrical Engineering-University of Engineering and Technology-Peru

Corresponding autor: PhD. Luis Aguilar Mendoza. luis.aguilar@upch.pe 


\section{INTRODUCTION}

The autistic spectrum conditions are characterized by difficulties in social interaction and communication, with the presence of stereotyped behaviors and restricted interests (Wing, 1991). The prevalence of these conditions has increased significantly in recent years (Newschaffer et al, 2007); however, some aspects of this condition remain an enigma for science. There are no neurobiological markers for autism and it is assumed that it is a complex phenomenon with many variables of different levels (genetic, molecular, neurophysiological, psychological, behavioral, social).

In the search for neurobiological mechanisms involved in autism, a variety of neurophysiological tests have been used and attention has been paid to the sensory pathways, especially to the auditory pathway. This can be evaluated by evoked potentials; each path component is associated with certain latency. Through evoked potentials and registrations with encephalography, it is possible to know the auditory brainstem response; the method consists in stimulating the auditory pathway with a click. This mechanical stimulus is transformed into an electrical stimulus in the Corti organ and travels the auditory path until reaching the brainstem approximately in $12 \mathrm{~ms}$. In this period, five waves are presented, representing the passage of information by each nervous station. (Trinidad et al, 2008)

The implication of the brainstem in autism was proposed three decades ago (Klin, 1993). Its response is manifested through the presentation of waves in the electroencephalogram (EEG) record. Wave I reflects the electrical activity of the spiral ganglion; wave II reflects the activity of the posterior part of the anteroventral cochlear nucleus and the anterior zone of the posteroventral cochlear nucleus; wave III reflects the activity of the anterior part of the anteroventral ipsilateral cochlear and of the medial nucleus of body trapeziod nucleus; wave IV reflects the activity of the isolateral and contralateral cells of the medial superior olive and wave $\mathrm{V}$ reflects the activity of the cells of the lateral lemniscus and/or inferior colliculus.

The main objective of this study was to estimate the auditory brainstem response of the pulse click, taking into account the latency of waves I, III and V; the interpeaks I-III, I-V, III-V and the amplitude of wave $\mathrm{V}$; and relate them with the formal and pragmatic aspects of communication (Children's Communication Checklist, CCC-2) and the autism quotient (Autism Quotient, AQ) of the participants.

\section{METHODS}

\section{Participants}

The sampling, not probabilistic, was composed of 14 volunteers between 4 and 16 years old for the autistic group, and 13 volunteers for the control group. The autistic patients were previously diagnosed with Autistic Spectrum Disorder, based on the Wing triad and DSM-IV-TR or ICD-10 criteria: F84.0, F84.5. The participants did not present developmental disorders or psychiatric disorders that may affect the outcomes, such as major depression, obsessive - compulsive disorder, etc.; and they had no moderate or severe hearing difficulties.

\section{Procedure}

The ABR was registered in the neurophysiology laboratory of the Cayetano Heredia National Hospital following the International System of Electrodes Nomenclature 10-20, the active electrode was placed on the vertex $(\mathrm{Cz})$, the ground on the forehead $(\mathrm{Fz})$ and the ear references (left and right) on the mastoids (M1 and M2). It was considered a high-pass filter of 160 $\mathrm{Hz}$ and a low-pass filter of $3.2 \mathrm{kHz}$ with a rejection of artifacts of $50 \mu \mathrm{V}$. Each participant had four record windows (monaural for left and right ear, at $90 \mathrm{~dB}$ $40 \mathrm{~dB}$ ) against the pulse click (2000 reps).

In order to evaluate the formal and pragmatic aspects of the Communication, it was used the Children's Communication Checklist, CCC-2 (Bishop, 2003), Spanish version. To evaluate the autism quotient, it was used the Autism Quotient, AQ. The version for children was considered for participants between 4 and 11 years old (Auyeung et al, 2008) and the version for adolescents was considered for participants between 11 and 16 years old (Baron-Cohen et al, 2006). This instrument allows to quantify the autistic traits and is used for research and clinical practice. 


\section{Statistics}

The data were analyzed with the statistical package STATA 12.0. In the specific comparative objectives, the T-Test has been used for the data distributed with normality and the Mann-Whitney U-Test has been used for the data that are not distributed normally. In the specific correlational objectives, a multiple regression was used, taking into account the AQ and CCC 2 as response variables and the $\mathrm{ABR}$ indexes, as predictor variables.

\section{RESULTS}

Autism quotient of the autistic group and the control group

The AQ score range for children is 0 to 150,0 being the extreme value that indicates the absolute absence of autistic features, and 74 the recommended cut-off point, which indicates the presence of autistic features that would justify a diagnostic. The autistic group of children $(n=7)$ had a mean of 80.4 , while the control group of children $(n=8)$ obtained an average of 62.33. The difference between both groups is significant $(\mathrm{p}<0.05)$. Therefore, the instrument is validated and it is assumed that the Autism Quotient is a variable that differentiates both groups of children. In the adolescents, the score range is from 0 to 50,0 being the extreme value that indicates the absolute absence of autistic features. The recommended cutoff point is 30, this indicates the presence of autistic features that would justify a diagnostic evaluation. The adolescent autistic group $(\mathrm{n}=7)$ obtained an average of 33.14; while the adolescent control group $(n=6)$ obtained an average of 18 . The difference between both groups is also significant $(\mathrm{p}<0.05)$. Therefore, the instrument is validated and it is assumed that the quotient of autism is a variable that differentiates both groups of adolescents.

Table 1 shows the percentage of children and adolescents on the cut-off point for the autistic group $(>\mathrm{C})$ and below the cut-off point for the control group $(<\mathrm{C})$. All scores exceed $50 \%$ and just one reaches $100 \%$, which confirms the differences between both groups, depending on this variable.

Table 1. Comparison of Autism Quotient between autistic group and control group

\begin{tabular}{lccccccccccc}
\hline AQ & \multicolumn{4}{c}{ autistic group $(\mathbf{n = 1 4})$} & \multicolumn{5}{c}{ control group $(\mathbf{n = 1 3})$} \\
& mean & s.d & $\min$ & $\max$ & $>$ C & mean & s.d & $\min$ & $\max$ & $<\mathrm{C}$ & $\mathrm{p}$ \\
\hline children & 80.4 & 9.21 & 72 & 96 & $80 \%$ & 10.54 & 10.54 & 43 & 75 & $75 \%$ & 0.00076 \\
adolescents & 33.14 & 7.12 & 23 & 43 & $57 \%$ & 4.89 & 4.89 & 14 & 24 & $100 \%$ & 0.0023 \\
\hline
\end{tabular}

Formal and pragmatic aspects of the communication of the autistic group and the control group

The same instrument was used for children and adolescents. The general communication composite score (GCC), serves to identify children and adolescents with significant language problems. The cut-off point that the authors of the test consider is 64, the lowest scores indicate major problems. The autistic group obtained an average of 43.73 and the control group had an average of 73.22; as expected, people with autism exhibit significant language problems and neurotypical people do not. The GCC difference between both groups was significant $(\mathrm{p}<0.05)$.

The instrument allows to differentiate linguistic profiles in function of the formal aspects (the first four scales: A, B, C and D) and pragmatic aspects (the four following: $\mathrm{E}, \mathrm{F}, \mathrm{G}$ and $\mathrm{H}$ )

(table 2). Those who have a typical development have both formal and pragmatic difficulties in the same proportion; those who have the autism spectrum condition have more pragmatic difficulties 
than formal difficulties. In most scales referring to the formal aspects: speech, syntax and semantics, as expected, there were no significant differences between both groups $(p>0.05)$. In all scales referring to the pragmatic aspects: inappropriate initiation, language stereotyping, use of context and non-verbal communication, as expected, there were significant differences between groups $(\mathrm{p}<0.05)$. Also, in the social relations and interests, there were significant differences. Therefore, the instrument is validated and it is assumed that the formal and pragmatic aspects constitute a variable which differentiates the autistic group and the control group.

Table 2. Comparison of CCC 2 between autistic group and control group

\begin{tabular}{|c|c|c|c|c|c|c|c|c|c|}
\hline \multirow{2}{*}{ CCC 2} & \multicolumn{4}{|c|}{ autistic group $(n=14)$} & \multicolumn{3}{|c|}{ Control group $(n=13)$} & \multirow[b]{2}{*}{$\max$} & \multirow[b]{2}{*}{$\mathrm{p}$} \\
\hline & mean & s.d & $\min$ & $\max$ & mean & s.d & $\min$ & & \\
\hline GCC & 43.73 & 10.45 & 25 & 65 & 73.222 & 21.987 & 37 & 98 & 0.0005 \\
\hline A. Speech & 7.455 & 3.045 & 1 & 12 & 8.556 & 3.812 & 1 & 12 & 0.4814 \\
\hline B. Syntax & 7.182 & 3.125 & 2 & 12 & 9.222 & 4.324 & 2 & 14 & 0.1780 \\
\hline C. Semantics & 7.091 & 1.973 & 2 & 12 & 9.556 & 3.972 & 2 & 16 & 0.0870 \\
\hline D. Coherence & 5.273 & 1.954 & 3 & 8 & 9.111 & 3.856 & 3 & 13 & 0.0097 \\
\hline E. Inappropriate initiation & 6 & 2.049 & 3 & 9 & 10.333 & 3.855 & 7 & 15 & 0.0013 \\
\hline F. Language stereotyping & 4.091 & 1.3 & 2 & 6 & 7.778 & 3.114 & 3 & 12 & 0.0021 \\
\hline G. Use of context & 3.545 & 2.162 & 1 & 8 & 9.778 & 3.682 & 5 & 14 & 0.0001 \\
\hline H. Non-verbal communication & 3.091 & 1.578 & 1 & 6 & 8.889 & 2.977 & 3 & 12 & 0.0001 \\
\hline I. Social relation & 4.727 & 2.24 & 1 & 8 & 9.667 & 2 & 7 & 14 & 0.0001 \\
\hline J. Interests & 4.364 & 1.963 & 1 & 9 & 9.111 & 4.4 & 3 & 16 & 0.0047 \\
\hline
\end{tabular}

\section{Auditory brainstem response of the autistic group and the control group}

The ABR includes the latency of waves I, III and $\mathrm{V}$; the interpeaks I-III, III-V and I-V; and the amplitude of wave V. Table 3 presents the responses obtained after a monaural stimulation with the pulse click at 90 $\mathrm{dB}$. The mean values of wave I, III and V latencies, the interpeaks I-III and the amplitude of wave V were higher in the autistic group. In contrast, the mean values of the interpeaks III-V and I-V were higher in the control group. However, the comparison between the groups reveals that there is only one difference in wave I latency, on both the left and the right, and the amplitude of the left wave V $(\mathrm{p}<0.05)$. 
Table 3. Comparison of Auditory Brainstem Response between autistic group and control group

\begin{tabular}{|c|c|c|c|c|c|c|c|c|c|}
\hline \multirow[t]{2}{*}{ ABR } & \multicolumn{4}{|c|}{ autistic group $(n=14)$} & \multicolumn{4}{|c|}{ control group $(n=13)$} & \multirow[b]{2}{*}{$\mathrm{p}$} \\
\hline & mean & s.d & $\min$ & $\max$ & mean & s.d & $\min$ & $\max$ & \\
\hline Wave I left $(+) *$ & 1.431 & 0.080 & 1.35 & 1.68 & 1.363 & 0.050 & 1.28 & 1.45 & 0.0069 \\
\hline Wave I right $(+) *$ & 1.490 & 0.285 & 1.30 & 2.46 & 1.368 & 0.094 & 1.22 & 1.59 & 0.0436 \\
\hline Wave III left (+) & 3.729 & 0.232 & 3.48 & 4.25 & 3.622 & 0.144 & 3.42 & 3.84 & 0.1980 \\
\hline Wave III right (+) & 3.751 & 0.243 & 3.48 & 4.38 & 3.625 & 0.136 & 3.44 & 3.84 & 0.1741 \\
\hline Wave V left (+) & 5.518 & 0205 & 5.16 & 5.80 & 5.463 & 0.236 & 5.01 & 5.77 & 0.5344 \\
\hline Wave V right (+) & 5.569 & 0.215 & 5.24 & 5.96 & 5.445 & 0.234 & 5.02 & 5.91 & 0.1859 \\
\hline Interpeaks I-III left (+) & 2.297 & 0.250 & 1.89 & 2.81 & 2.259 & 0.124 & 5.02 & 5.91 & 0.6263 \\
\hline Interpeaks I-III right (+) & 2.260 & 0.205 & 1.92 & 2.71 & 2.257 & 0.114 & 2.04 & 2.40 & 0.9623 \\
\hline Interpeaks III-V left (-) & 1.787 & 0.197 & 1.46 & 2.13 & 1.840 & 0.188 & 1.45 & 2.20 & 0.4830 \\
\hline Interpeaks III-V right (-) & 1.818 & 0.192 & 1.53 & 2.13 & 1.823 & 0.208 & 1.35 & 2.15 & 0.9465 \\
\hline Interpeaks I-V left (-) & 4.084 & 0.246 & 3.48 & 4.37 & 4.099 & 0.204 & 3.69 & 4.37 & 0.8656 \\
\hline Interpeaks I-V right (-) & 4.078 & 0.234 & 3.50 & 4.33 & 4.080 & 0.195 & 3.69 & 4.32 & 0.9797 \\
\hline Amplitude wave V left $(+) *$ & 0.520 & 0.134 & 0.308 & 0.794 & 0.404 & 0.119 & 0.159 & 0.653 & 0.0250 \\
\hline Amplitude wave V right (+) & 0.510 & 0.135 & 0.320 & 0.732 & 0.455 & 0.075 & 0.351 & 0.647 & 0.2141 \\
\hline
\end{tabular}

(+) Higher mean value between the autistic group and control group, (-) lower mean value between the autistic group and control group. $*=p<0.05$

When analyzing the auditory response of the brainstem individually (table 4), to estimate the prevalence of abnormalities (using the mean of the control group +/- 2SD as the upper and lower limit), it was observed that in the autistic group, in 11 of the 14 indexes, there were abnormal cases; $21.42 \%$ had an abnormal prolongation of nterpeaks I-III-left;
$21.42 \%$ had an abnormal amplitude of left wave $\mathrm{V}$ and $28.56 \%$ had an abnormal amplitude of right wave V. In the control group, only 5 of the 14 indexes showed abnormal cases and it had a lower percentage. In almost all indexes, the subjects of this group presented normal latencies $(\% \mathrm{LN}=100)$. 
Table 4. Prevalence of Auditory Brainstem Response abnormalities in autistic group and control group

\begin{tabular}{lcccccc}
\hline ABR abnormalities & \multicolumn{3}{c}{ autistic group (n=14) } & \multicolumn{2}{c}{ control group (n=13) } \\
& \% LP & \% LC & \% LN & \% LP & \% LC & $\%$ LN \\
\hline Wave I left & 7.14 & 0 & 92.86 & 0 & 0 & 100 \\
Wave I right & 7.14 & 0 & 92.86 & 7.69 & 0 & 92.31 \\
Wave III left & 14.28 & 0 & 85.72 & 0 & 0 & 100 \\
Wave III right & 14.28 & 0 & 85.72 & 0 & 0 & 100 \\
Wave V left & 0 & 0 & 100 & 0 & 0 & 100 \\
Wave V right & 7.14 & 0 & 92.96 & 0 & 0 & 100 \\
Interpeaks I-III left & 21.42 & 0 & 78.58 & 0 & 0 & 100 \\
Interpeaks I-III right & 14.28 & 7.14 & 78.58 & 0 & 0 & 100 \\
Interpeaks III-V left & 0 & 7.14 & 92.86 & 0 & 0 & 100 \\
Interpeaks III-V right & 0 & 0 & 100 & 0 & 0 & 100 \\
Interpeaks I-V left & 0 & 7.14 & 92.86 & 0 & 7.69 & 92.31 \\
Interpeaks I-V right & 0 & 7.14 & 92.86 & 0 & 7.69 & 92.31 \\
Amplitude wave V left & 21.42 & 0 & 78.58 & 7.69 & 7.69 & 84.62 \\
Amplitude wave V right & 28.36 & 0 & 71.44 & 7.69 & 0 & 92.31 \\
\hline
\end{tabular}

\% LP: Percentage of abnormal cases due to prolonged latency or high amplitude.

$\%$ LC: Percentage of abnormal cases due to short latency or low amplitude.

$\%$ LN: Percentage of cases with normal latencies and amplitudes.

Relationship between the formal and pragmatic aspects of communication, the quotient of Autism and the auditory brainstem response

A multiple regression analysis was performed, taking into account the AQ as response variable and $\mathrm{ABR}$ index as predictor variables. In the adolescent autistic group, the latency of the left and right wave $\mathrm{V}$ $(\mathrm{R} 2=0.955, \mathrm{p}<0.01)$, and left and right interpeaks I-V $(\mathrm{R} 2=0.988, \mathrm{p}<0.01)$, would be the only ABR index that would predict AQ. However, in the adolescent control group, only the latency of the right wave III reaches the AQ. On the other hand, taking into account CCC 2 as a response variable, it is observed that there are no ABR indexes that can predict the GCC or some scale. 


\section{DISCUSSION}

The comparative objectives have made it possible to validate the instruments for the Autism Quotient (AQ) and the formal and pragmatic Aspects of Communication (CCC 2). Due to the significant differences found, these variables are assumed to differentiate the autistic group from the control group. It has been found that the mean values of the latencies of wave I, III and V, interpeaks I-III and the amplitude of wave $\mathrm{V}$ are higher in the autistic group; while the mean values of interpeaks III-V and I-V are higher in the control group. However, the comparison between the two groups reveals that there is only one significant difference in the latency of wave I, on both the left and the right, and the amplitude of the left wave V. In these indexes the autistic group shows greater latency (one prolongation) and greater amplitude.

Similar results were reported by Ververi (2015), it was found a prolonged latency in all waves and interpeaks, but without statistical significance. Also, it was identified abnormal latencies (prolonged or shortened), $33 \%$ in the autistic group and $9 \%$ in the control group.

In our research, we also found more frequent cases of abnormality in the autistic group, being mostly abnormal cases by prolonged latency or high amplitude: $28.56 \%$ had an abnormal amplitude of right wave V; $21.42 \%$ had an abnormal amplitude of left V wave; $21.42 \%$ had an abnormal prolongation of left interpeak I-III; $14.28 \%$ had an abnormal prolongation of left wave III, right wave III and left interpeak IIII; and 7.14\% had an extension form of left wave I , right wave I and right wave V. Although it was also identified abnormal cases due to shortened latency: $7.14 \%$ had a short latency of right interpeak I-III, left interpeak III-V, left interpeak I-V and right interpeak I-V. In contrast, in the control group, fewer cases of abnormality were identified, only $7.69 \%$ showed prolonged latency in right wave I, high amplitude of left - right wave V, short latency of left - right I - V interpeak, and short amplitude of left wave V.

In another age range: 8-20 years, Magliaro (2010) found significant differences between the autistic group and the control group in the latency of wave III and $\mathrm{V}$, interpeak I-III and I-V. In other investigations with different age ranges, differences have also been found, which tend to be the prolongation of latencies in the autistic group. However, most of the studies do not report significant differences in all waves, only in some (Rosenhall et al., 2003; Tas et al., 2007, Kwon et al., 2007, Fujikawa-Brooks et al., 2010; Russo et al, 2010; Dabbous et al, 2012; Miron et al, 2015). Probably, these results are still inconsistent in the studied groups and these respond to the differences in the sample selection and the methodology (the protocol of stimulation).

Especially, the prolongation of wave I has been reported in the literature, Rosenhall (2003) identified a longer wave I in $24 \%$ of people with autistic spectrum condition $(n=101)$ and points out that it is possible that the prolongation reflects a slowing of the synaptic processes in the organ of Corti (as seen in patients with tinnitus). According to Rosenhall, cross olivocochlear beam $(\mathrm{COCB})$ would be closely related to wave I. $\mathrm{COCB}$ is an efferent system constituted by neurons of the median olivary complex and efferent neurons that pass from the vestibular nerve to the cochlea; this system modulates cochlear function by acting on cells, and some studies suggest that it may influence the ability of the ear to develop resistance to noise trauma.

About the relationship between the AQ and the $\mathrm{ABR}$, we found that there are significant values only in the group of adolescents; the latency of the left and right wave $\mathrm{V}$, and the left and right interpeak I-V would be the only ABR indexes that would predict AQ (p $<0.05$ ). As regards the relationship between CCC 2 and $\mathrm{ABR}$, there was only a significant relationship between the left interpeak III-V and the coherence. The studies that are related to $A B R$ with social interaction variables and communication (Geva, 2011), inhibitory behavior (Geva, 2014) and repetitive behaviors (Cohen, 2013) have been performed in infants or young children. This study is one of the first works with a variable of the severity of autism and has obtained positive results in a group of adolescents. However, why has not a positive result been achieved in the group of children? Roth (2012) notes that the latencies of ABR waves are extended by the age at which symptoms are evident ( 2 to 4 years). 
In conclusion, the instrument is validated and it is assumed that the autism quotient and the formal and pragmatic aspects are variables that differentiate both groups. There are significant differences between the auditory brainstem response of the autistic group and the control group. Furthermore, there is a significant correlation in the adolescent autistic group between the AQ with four indexes of the auditory brainstem response and the adolescent control group with one index. How will ABR waves be in autistic adults? Will there be a phenomenon of adaptability? To understand better the relationship between ABR waves and symptoms, it is necessary to conduct studies with a large sample, with people with different degrees of severity of autism and with people of different ages (from neonates to adults) to observe the ABR throughout the development cycle. Cross-sectional studies appear to be a good option.

\section{Compliance with Ethical Standards}

\section{Funding}

This study was funded by "Fondo para la innovación, la Ciencia y la Tecnología (FINCyT)Perú" (Proyect: 146-PNICP-PIAP-2015).

\section{Ethical Approval}

All procedures performed in this study were in accordance with the 1964 Helsinki declaration and the protocol was approved by the ethical committee of Cayetano Heredía University.

\section{Informed Consent}

All participants included in this study or their attorneys signed an informed consent. Conflict of Interest: Marilia Baquerizo Sedano declares that she has no conflict of interest. Edward Susanibar Mesías declares that he has no conflict of interest. Mario Wong Egusquiza declares that he has no conflict of interest. David Achanccaray Diaz declares that he has no conflict of interest. Christian Flores Vega declares that he has received research grants from

"Fondo para la innovación, la Ciencia y la Tecnología (FINCyT)-Perú" Project: 146-PNICPPIAP-2015 and has no conflict of interest. Luis Baquerizo Sedano declares that he has no conflict of interest. Hugo Umeres Cáceres declares that he has no conflict of interest. Luis Aguilar Mendoza declares that he has no conflict of interest.

\section{Acknowledgments}

We wish to thank all the children and families who took part of this study. Author Contributions

This study was conceived by MBS, in discussion with LAM. ESM designed the study and collected the data. Data analysis was done by LBS and MWE. MBS coordinated and drafted the manuscript with contributions from LAM. All authors read and approved the final manuscript.

\section{REFERENCES}

Auyeung, B., Baron-Cohen, S., Wheelwright, S., \& Allison, C. (2008). The autism spectrum quotient: Children's version (AQ-Child). Journal of autism and developmental disorders, 38(7), 1230-1240

Baron-Cohen, S., Hoekstra, R. A., Knickmeyer, R., \& Wheelwright, S. (2006). The autism-spectrum quotient (AQ) - adolescent version. Journal of autism and developmental disorders, 36(3), 343350 .

Bishop, D. V. (2003). The Children's Communication Checklist: CCC-2. London: Harcourt Assessment.

Cohen, I. L., Gardner, J. M., Karmel, B. Z., Phan, H. T., Kittler, P., Gomez, T. R., ... \& Barone, A. (2013). Neonatal Brainstem Function and 4Month Arousal-Modulated Attention Are Jointly Associated With Autism. Autism Research, 6(1), 11-22.

Dabbous, A. O. (2012). Characteristics of auditory brainstem response latencies in children with autism spectrum disorders. AudiologicalMedicine, 10(3), 122-131

Fujikawa-Brooks, S., Isenberg, A. L., Osann, K., Spence, M. A., \& Gage, N. M. (2010). The effect of rate stress on the auditory brainstem response in autism: a preliminary report.International journal of audiology, 49(2), 129-140. 
Geva, R., Sopher,K., Kurtzman,L., Galili, G.,Feldman, R., \& Kuint, J. (2011). Neonatal brainstem dysfunction risks infant social engagement. Social cognitive and affective neuroscience, 8(2), 158-164.

Geva, R., Schreiber, J., Segal-Caspi, L., \& MarkusShiffman, M. (2014). Neonatal brainstem dysfunction after preterm birth predicts behavioral inhibition. Journal of Child Psychology and Psychiatry, 55(7), 802-810.

Klin, A. (1993). Auditory brainstem responses in autism: brainstem dysfunction or peripheral hearing loss?.Journal of autism and developmental disorders, 23(1), 15-35.

Kwon, S., Kim, J., Choe, B. H., Ko, C., \& Park, S. (2007). Electrophysiologic assessment of central auditory processing by auditory brainstem responses in children with autism spectrum disorders. Journal of Korean medical science, 22(4), 656-659.

Magliaro, F. C. L., Scheuer, C. I., Assumpção Júnior, F. B., \& Matas, C. G. (2010). Estudo dos potenciais evocados auditivos em autismo. Pró-Fono Revista de Atualização Científica, 22(1), 31-36.

Miron, O., Ari-Even Roth, D., Gabis, L. V., Henkin, Y., Shefer, S., Dinstein, I., \& Geva, R. (2015). Prolonged auditory brainstem responses in infants with autism. Autism Research. 9(6), 689-95.

Newschaffer CJ1, Croen LA, Daniels J, Giarelli E, Grether JK, Levy SE, Mandell DS, Miller LA, Pinto-Martin J, Reaven J, Reynolds AM, Rice CE, Schendel D, Windham GC. (2007) The epidemiology of autism spectrum disorders. Annual Review of Public Health, 28:235-58.

Rosenhall, U., Nordin, V., Brantberg, K., \& Gillberg, C. (2003). Autism and auditory brain stem responses. Ear and hearing, 24(3), 206-214.

Roth, D.A.E., Muchnik, C., Shabtai, E., Hildesheimer, M., \& Henkin, Y. (2012). Evidence for atypical auditory brainstem responses in young children with suspected autism spectrum disorders. Developmental Medicine \& Child Neurology, 54(1), 23-29

Russo, N. M., Hornickel, J., Nicol, T., Zecker, S., \& Kraus, N. (2010). Biological changes in auditory function following training in children with autism spectrum disorders. Behavioral and Brain Functions, 6(1), 1.

Tas, A., Yagiz, R., Tas, M., Esme, M., Uzun, C., \& Karasalihoglu, A. R. (2007). Evaluation of hearing in children with autism by using TEOAE and ABR. Autism, 11(1), 73-79.

Trinidad, Y, Trinidad, G \& De la Cruz, E (2008) An Ped Contin. 2008; 6(5):296-301

Wing, L. (1991). The relationship between Asperger's syndrome and Kanner's autism. Autism and Asperger syndrome, 93-121.

Ververi, A., Vargiami, E., Papadopoulou V., Tryfonas, D., \& Zafeiriou, D. (2015). Brainstem Auditory Evoked Potentials in Boys with Autism: Still Searching for the Hidden Truth. Iranian journal of child neurology, 9(2), 2 